\title{
Experiment on the Internal Configuration of Electricity-Generating Tuned Mass Piezo-Damper
}

\author{
J. Oh, D-H. Ha, J. F. Choo, D-H. Lee and E. S. Cho
}

\begin{abstract}
The Tuned Mass Piezo-Damper (TMPD) is a Tuned Mass Damper (TMD) in which the dampers are replaced by piezocomposite elements to allow the device harvest electric power from the vibrational energy in addition to its vibration control function. This paper presents the experiment conducted to improve the electricity-generating performance of the TMPD. The results are presented with respect to the configuration adopted to excite the piezocomposite elements in the TMPD.
\end{abstract}

Index Terms-Energy harvesting, piezoelectric, Tuned Mass Piezo-Damper, TMD.

\section{INTRODUCTION}

Civil structures like bridges are continuously subjected to external forces such as wind and traffic load against which their safety must be secured since the design stage. With the development of materials and construction technology together with the will to create landmark structures, modern bridges tend to have wider span and thinner deck. These structures are prone to vibration and may undergo excessive deformations. This problem is often dealt by means of the Tuned Mass Damper (TMD), which is a passive control device composed of a mass, springs, and dampers that can effectively reduce vibration.

To endow the TMD with additional electricity-harvesting function, the authors conceived the Tuned Mass Piezo-Damper (TMPD) shown in Fig. 1 [1]-[2]. The TMPD is the TMD in which the dampers are replaced by piezocomposite elements. Recalling that piezoelectricity is the electric charge that accumulates in certain solid materials in response to applied mechanical stress, the TMPD can harvest energy from the vibration energy of the structure induced by external loads. A former study showed that the so-generated electrical energy can be used to power the monitoring system or the bridge's facilities [1]. This paper presents the results of experiments conducted to improve the electricity-generating performance of the TMPD.

J. Oh is with the Civil Engineering Dept. of Konkuk University, Seoul, Korea

D-H. Hais with the Civil Engineering Department of Konkuk University, Seoul, Korea

J. F. Choo is with the Energy Engineering Department of Konkuk University, Seoul, Korea

D-H. Lee is with the Civil Engineering Department of Konkuk University, Seoul, Korea

E. S. Chon is with the Civil Engineering Department of Konkuk University, Seoul, Korea
The results are presented with respect to the configuration adopted to excite the piezocomposite elements in the TMPD.

\section{TMPD}

Fig. 2 shows the TMPD that was designed and fabricated in this study. The TMPD is enclosed in a rectangular frame that will move vertically along linear guides attached to the fixed jig. The rectangular frame is supported by a roller which is in contact with the platform of the shaking table through a curved surface so that the horizontal motion of the shaking table is converted into vertical motion of the frame. The moving part in the TMPD is the mass composed of steel plates stacked together. Since most pedestrian overpasses have natural frequency of about $2 \mathrm{~Hz}$, the natural frequency of the moving mass is also set to $2 \mathrm{~Hz}$. In this experiment, the weight of the mass was set $95 \mathrm{~kg}$ to match the natural frequency $2 \mathrm{~Hz}$. The piezocomposite elements are attached at both sides of the mass to accompany the motion of the mass. Generally, larger deformation of the piezocomposite elements provides larger electric power output. Therefore, a series of brush was attached on the frame of the TMPD to deform or excite the piezo-elements by hitting them during the motion of the mass [3].

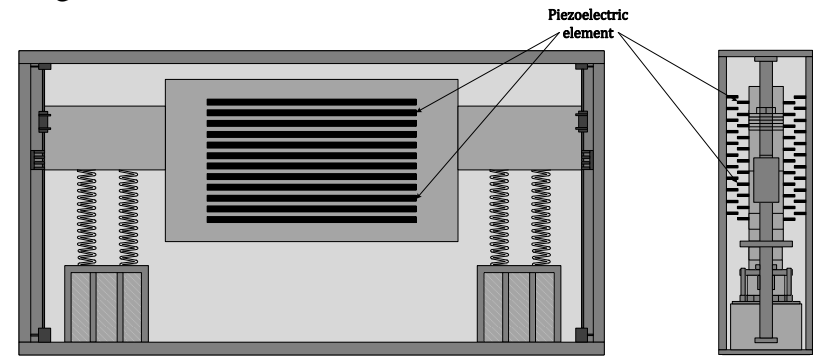

Fig. 1: The concept of TMPD

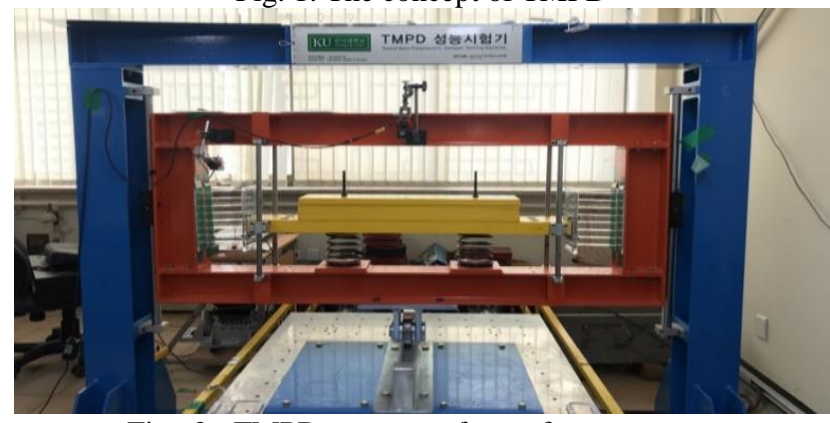

Fig. 2:. TMPD prototype for performance test. 


\section{LABORATORY TEST}

The brush-hitting configuration was selected following the results of a previous study [4]. In the previous study, the piezoelectric element was attached to the mass of the TMPD and it was expected that the cantilevered element would generate electric power just by the resulting free vibration of the element. However, this configuration was seen to be improper for power generation and for providing additional damping. Accordingly, another study [5] chose to hit the attached piezoelectric element with a soft material, i.e. brush, to excite the element and prevent its damage due to shock.

It was found that the adoption of the brush improved significantly the power generation efficiency of the TMPD. The voltage per piezoelectric element increased more than two times from $10.53 \mathrm{~V}$ to $25.56 \mathrm{~V}$, and the power increased about 69 times from $0.019 \mathrm{~mW}$ to $1.31 \mathrm{~mW}$. In addition, the damping capability of the TMPD could be verified with a damping ratio of $0.309 \%$. This confirmed that the brush was more effective than the cantilever method but could not provide the damping ratio of $2 \%$ that would have been brought by the conventional TMD nor generate enough power to be used for structure maintenance [5].

Consequently, this study adopts the brush-hitting method but uses other types of brush to increase the power output of piezoelectric element and the damping capacity. The considered brushes are shown in Fig. 3. Type 1 is very soft and thin (soft paint brush). Type 2-brush is the one used in [5] with slightly thicker and harder bristles than Type 1. Type 3 has bristles made of nylon that make the brush thinner and more rigid than the other types.

Fig. 4 shows the setup adopted to test the effect of the type of hitting brush on the performance of the TMPD. The overlap between the brush and the piezoelectric element is set unilaterally to $1 \mathrm{~mm}$. Two sets of 5 brushes and 5 piezoelectric elements and are disposed at both sides of the TMPD's mass giving a total of 10 piezoelectric elements to be hit by 10 brushes. The effect of the brush on the performance of the TMPD is measured by the maximum displacement of the piezoelectric element and corresponding voltage output when the piezoelectric element hit each brush. Fig. 5 plots the voltage output of the TMPD equipped with brush type 3 during about 1 minute of shaking table test at excitation of $2 \mathrm{~Hz}$.

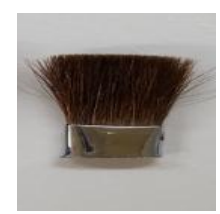

Type 1

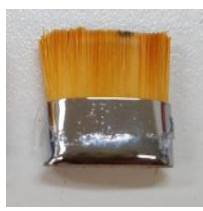

Type 2

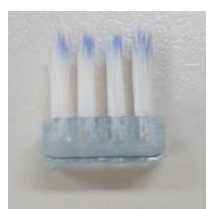

Type 3
Fig. 3: Considered types of hitting brush.

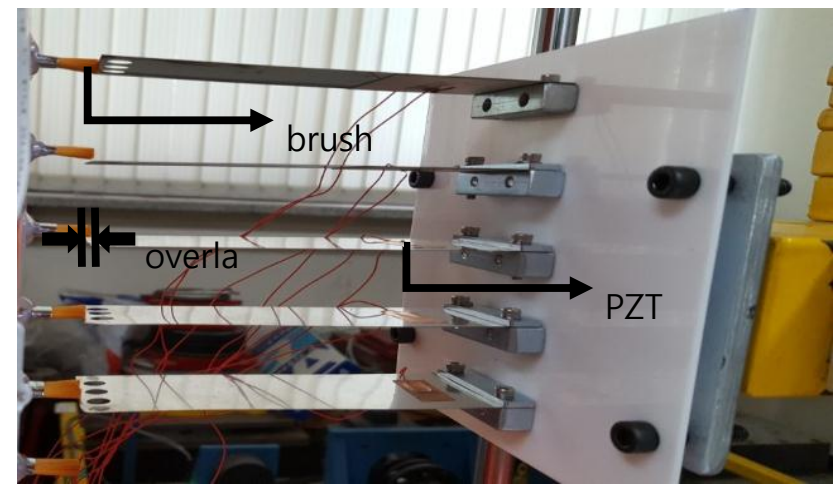

Fig. 4: Configuration of brush-hitting system in TMPD.

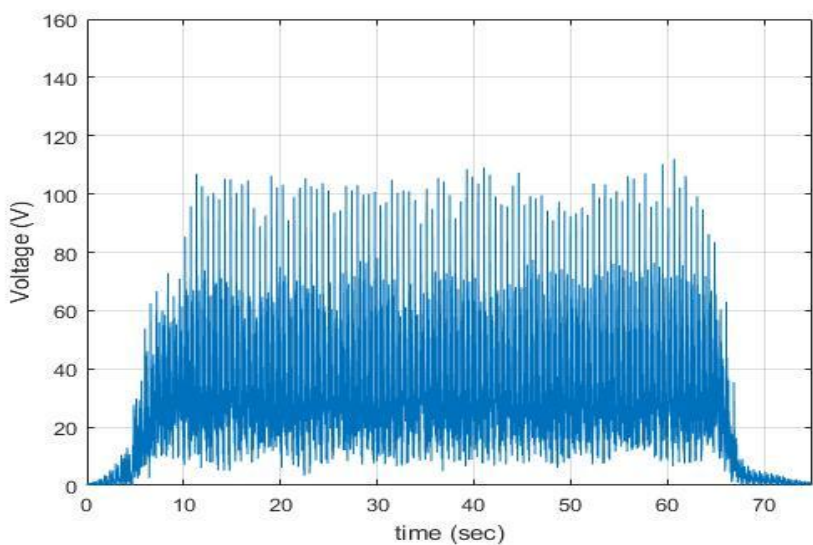

Fig. 5: Brush type 3 voltage (10ea)

Moreover, free vibration test was also conducted to evaluate the damping effect provided according to the type of brush. An initial displacement of $50 \mathrm{~mm}$ was applied to the mass of the moving part of the damper to induced free vibration. The displacement of the mass was measured using a laser displacement gauge (Fig. 6). The damping ratio is calculated by logarithmic decrement on the measured free vibration data (Figs. 7 and 8).

Table 1 arranges the damping ratio provided by the free vibration data of the TMPD equipped with 10 piezoelectric elements. It appears that brush type 3 provides a damping ratio of $0.351 \%$, which represents an increase by $66 \%$ compared to the $0.211 \%$ brought by brush type 1 .

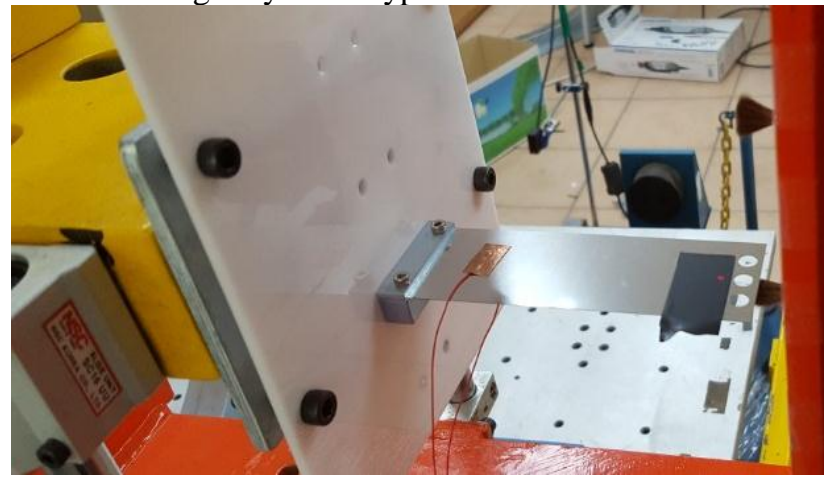

Fig. 6: TMPD's damping verification test. 


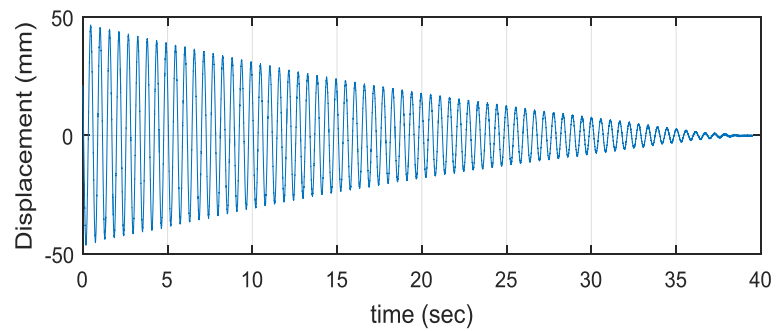

Fig. 7: Free vibration of the mass - Brush type 1

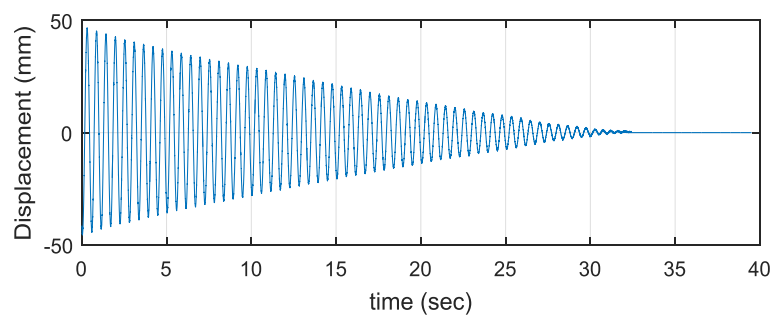

Fig. 8: Free vibration of the mass - Brush type 3

TABLE I: DAMPING RATIO ACCORDING TO HITTING-BRUSH TYPE

\begin{tabular}{|c|c|}
\hline Brush Type & Damping ratio (\%) \\
\hline Type1 & 0.211 \\
\hline Type2 & 0.309 \\
\hline Type3 & 0.351 \\
\hline
\end{tabular}

TABLE II: POWER GENERATION ACCORDING TO BRUSH-TYPE

\begin{tabular}{|c|c|c|c|}
\hline $\begin{array}{c}\text { Brush } \\
\text { type }\end{array}$ & $\begin{array}{c}\text { Maximum } \\
\text { displacement } \\
(\mathrm{mm})\end{array}$ & $\begin{array}{c}\text { Maximum } \\
\text { voltage } \\
(\mathrm{V})\end{array}$ & $\begin{array}{c}\text { Power } \\
(\mathrm{mW})\end{array}$ \\
\hline Type1 & 2.38 & 1.35 & 0.01 \\
\hline Type2 & 15.66 & 25.56 & 1.31 \\
\hline Type3 & 19.25 & 38.74 & 3.00 \\
\hline
\end{tabular}

Table 2 arranges the maximum displacement, the maximum voltage and the amount of power of one piezoelectric element according to the type of brush. The power is calculated for a matching resistance of $500 \mathrm{k} \Omega$.

As a matter of fact, the displacement at the tip of the piezoelectric element is seen to be larger with harder brush. As a result, the corresponding maximum voltage and power are also increased. Compared to type1, the voltage output of the TMPD using type 3 is increased from $1.35 \mathrm{~V}$ to $38.74 \mathrm{~V}$ and the power is increased from $0.01 \mathrm{~mW}$ to $3.00 \mathrm{~mW}$.

\section{CONCLUSION}

In this paper, an experiment was conducted to improve the vibration control and power production capability of the Tuned Mass Piezo-Damper, a TMD in which the dampers are replaced by piezocomposite elements. The results showed that using brushes to hit or excite the piezoelectric element inside the TMPD was recommended to prevent damage of the element. Furthermore, the experiment conducted using three types of brush with different softness and thickness revealed that the use of a thin brush with rough bristles provided improved power generation and damping capacity. However, further studies should be conducted to ameliorate the damping capacity to a level comparable to the conventional TMD. Nevertheless, it is expected that more efficient power generation will be possible by using the relation that the thinner, the larger the strength, the more the displacement and the generated voltage output.

\section{ACKNOWLEDGMENT}

This work is financially supported by Korea Ministry of Land Infrastructure and Transport (MOLIT) as "Smart City Master and Doctor Course Grant Program”.

\section{REFERENCES}

[1] J. F. Choo, D. H. Ha, and H. K. Han, "Evaluation of energy-producing capability from pedestrian-induced vibration in footbridge by a new Tuned Mass Piezo-Damper," KSCE J. Civ. Eng., vol.21, pp. 2322-2328, 2017. https://doi.org/10.1007/s12205-016-2817-y

[2] H. K. Han, K. W. Seong, D. H. Ha, and J. F. Choo, "Concept of a multi-functional tuned mass damper with built-in piezocomposite element," Proceedings of 2015 Spring Conference of KSMI, pp. 463-464 (in Korean).

[3] M. Suh, D. H. Ha, J. F. Choo, H. Han, and D. Lee, "Development of test prototype for electricity-generation tuned-mass-damper," International Conference on Electronics, Computer and Information Technology, pp. 153-157, 2016.

[4] D. H. Lee, D. H. Ha, J. F. Choo, E. S. Cho, "Verification for Damping and Power Generation Efficiency of Tuned-Mass-Piezoelectric-Damper," in Proc. 2017 Earthquake Engineering Society of Korea Conf., 2017, pp. 101-102.

[5] D. H. Lee, D. H. Ha, J. F. Choo, and M. S. Suh, "Testing of a New Electricity-Generating TMD by Shaking Table," in Proc. 2016 AMSEE Conf., 2016, pp. 101-104.

https://doi.org/10.2991/amsee-16.2016.28

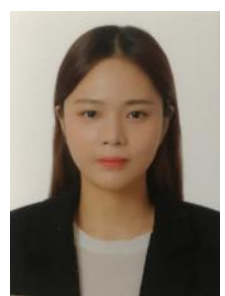

J. Oh is born in Seoul, Korea, in 1995. She enrolled in the Civil Engineering Department at Hongik University in 2014 and obtained her BS in 2018 and enrolled the Graduate Program of the same department at Konkuk University in 2018 